\title{
X-chromosome terminal deletion in a female with premature ovarian failure: Haploinsufficiency of X-linked genes as a possible explanation
}

\author{
Susana I Ferreira', Eunice Matoso ${ }^{1,4}$, Marta Pinto1', Joana Almeida², Thomas Liehr ${ }^{3}$, Joana B Melo ${ }^{1,5}$,
} Isabel M Carreira ${ }^{1,4,5^{*}}$

\begin{abstract}
Background: Premature ovarian failure (POF) has repeatedly been associated to X-chromosome deletions. FMR1 gene premutation allele's carrier women have an increased risk for POF. We intent to determine the cause of POF in a 29 year old female, evaluating both of these situations.

Methods: Concomitant analysis of FMR1 gene CGG repeat number and karyotype revealed an X-chromosome terminal deletion. Fluorescence in situ further characterized the breakpoint. A methylation assay for FMR1 gene allowed to determine its methylation status, and hence, the methylation status of the normal X-chromosome.

Results: We report a POF patient with a 46,X,del(X)(q26) karyotype and with skewed X-chromosome inactivation of the structural abnormal X-chromosome.

Conclusions: Despite the hemizygosity of FMR1 gene, the patient does not present Fragile $X$ syndrome features, since the normal $X$-chromosome is not subject to methylation. The described deletion supports the hypothesis that haploinsufficiency of $X$-linked genes can be on the basis of POF, and special attention should be paid to Xlinked genes in region Xq28 since they escape inactivation and might have a role in this disorder. A full clinical and cytogenetic characterization of all POF cases is important to highlight a pattern and help to understand which genes are crucial for normal ovarian development.
\end{abstract}

\section{Background}

Premature ovarian failure (POF) is an early ovarian dysfunction characterized by the cessation of menses before the age of 40 years [1,2] that affects $1 \%$ of women [3]. The diagnosis is established by the presence of FSH (follicle stimulating hormone) serum level higher than 40 $\mathrm{mIU} / \mathrm{ml}[4]$, detected on at least two occasions a few weeks apart [5]. Although the exact etiology is still unknown, several causes have been associated with POF and may include autoimmunity, infections, iatrogenesis and a strong genetic component, that can vary from single gene alterations to chromosome abnormalities [6].

$\mathrm{X}$; autosome balanced translocations and X-chromosome deletions have been reported in POF patients, leading to the identification of two main critical regions

\footnotetext{
* Correspondence: i_marques@hotmail.com

'Laboratório de Citogenética, Instituto de Biologia Médica, Faculdade de Medicina, Universidade de Coimbra, 3000-354 Coimbra, Portugal
}

for normal ovarian function on the long arm of this chromosome, specifically at Xq13-q21 [7] and Xq26-q27 $[4,8]$. In the case of X;autosome balanced translocations, these can either lead to gene disruption at the rearrangement breakpoints, or to a position effect alteration, changing the normal expression of genes involved in ovarian function [9]. X-linked genes known to escape inactivation can also be responsible for the occurrence of POF associated with total or partial monosomies of the X-chromosome, reflecting a situation of haploinsufficiency for those genes [9].

One of the genes known to be associated with POF is FMR1 (Fragile $\mathrm{X}$ mental retardation), located at Xq27.3 and responsible for Fragile X Syndrome (FXS). It is a form of X-linked mental retardation caused by the expansion of an instable CGG repeat in the 5 ' untranslated region of the gene $[1,10]$. The syndrome occurs when the number of the repeats exceeds 200 , being

C Biomed Central

C 2010 Ferreira et al; licensee BioMed Central Ltd. This is an Open Access article distributed under the terms of the Creative Commons Attribution License (http://creativecommons.org/licenses/by/2.0), which permits unrestricted use, distribution, and reproduction in any medium, provided the original work is properly cited. 
denominated as full mutation alleles. This is responsible for hypermethylation and gene inactivation, leading to absence of FMRP (Fragile X mental retardation protein) and, consequently, causing mental retardation [11]. Men with full mutation alleles are always affected, whereas only one third of women are so, due to X-chromosome inactivation [10]. Several studies have been associating FMR1 premutation alleles, which may have 55 to 200 CGG repeats, and POF, with approximately $20 \%$ of premutation carrier women being affected [11]. Since full mutation carriers do not have an increased risk for ovarian dysfunction, the molecular mechanism underlying the association between POF and premutation alleles, although still unravelled, should not be related to the absence or reduction of FMRP [12].

The present case was referred as part of a study group of women with POF for the evaluation of their karyotypes and association to the FMR1 gene CGG repeat number. We report a case of a 29 year old woman with a de novo Xq26 to Xqter deletion that includes FMR1 gene associated with POF. Besides having only one functional allele prone to suffer inactivation, she has no FXS symptoms.

\section{Results}

\section{FMR1 repeats determination}

FMR1 gene CGG repeat number evaluation revealed the presence of only one allele (Figure 1). A woman with a normal karyotype would have three peaks for this analysis, the first one corresponding to the X-chromosome and the other two corresponding to the two alleles of FMR1 gene. After repeating the analysis, in order to exclude an amplification failure during PCR reaction, the result was confirmed, being present only one allele with 20 CGG repeats.

\section{Cytogenetic analysis}

GTG high resolution banded metaphase spreads from the subject were analyzed and revealed a large terminal deletion in the long arm of one of the X-chromosomes in all 10 metaphases studied (Figure 2A). Conventional cytogenetics results suggest a probable deletion breakpoint between bands Xq25-q26, being her final karyotype $46, X, \operatorname{del}(X)(q 25 \sim q 26)$. The subject's mother karyotype was normal. As the father had already deceased it was not possible to perform cytogenetics analysis.

\section{Fluorescence in situ hybridization}

FISH analysis with the subtelomeric specific probe DXYS61 showed only one signal for Xqter in all metaphases scored, confirming the conventional banding cytogenetic findings (Figure 2B). The integration of $\mathrm{MCB}$ and BAC probes results allowed us to conclude with more precision that the deletion breakpoint is at Xq26 (Figure 3). The breakpoint was between 128.660 $\mathrm{Mb}$ and $133.964 \mathrm{Mb}$.

\section{FMR1 methylation analysis}

This analysis revealed that the $\mathrm{X}$-chromosome subjected to methylation was the one with the qter deletion, as all probes with HhaI recognition site were digested, meaning that they were not methylated in the normal allele present (Figure 4). Although visual analysis was quite conclusive, the methylation status was further analyzed with the Coffalyser software which revealed a

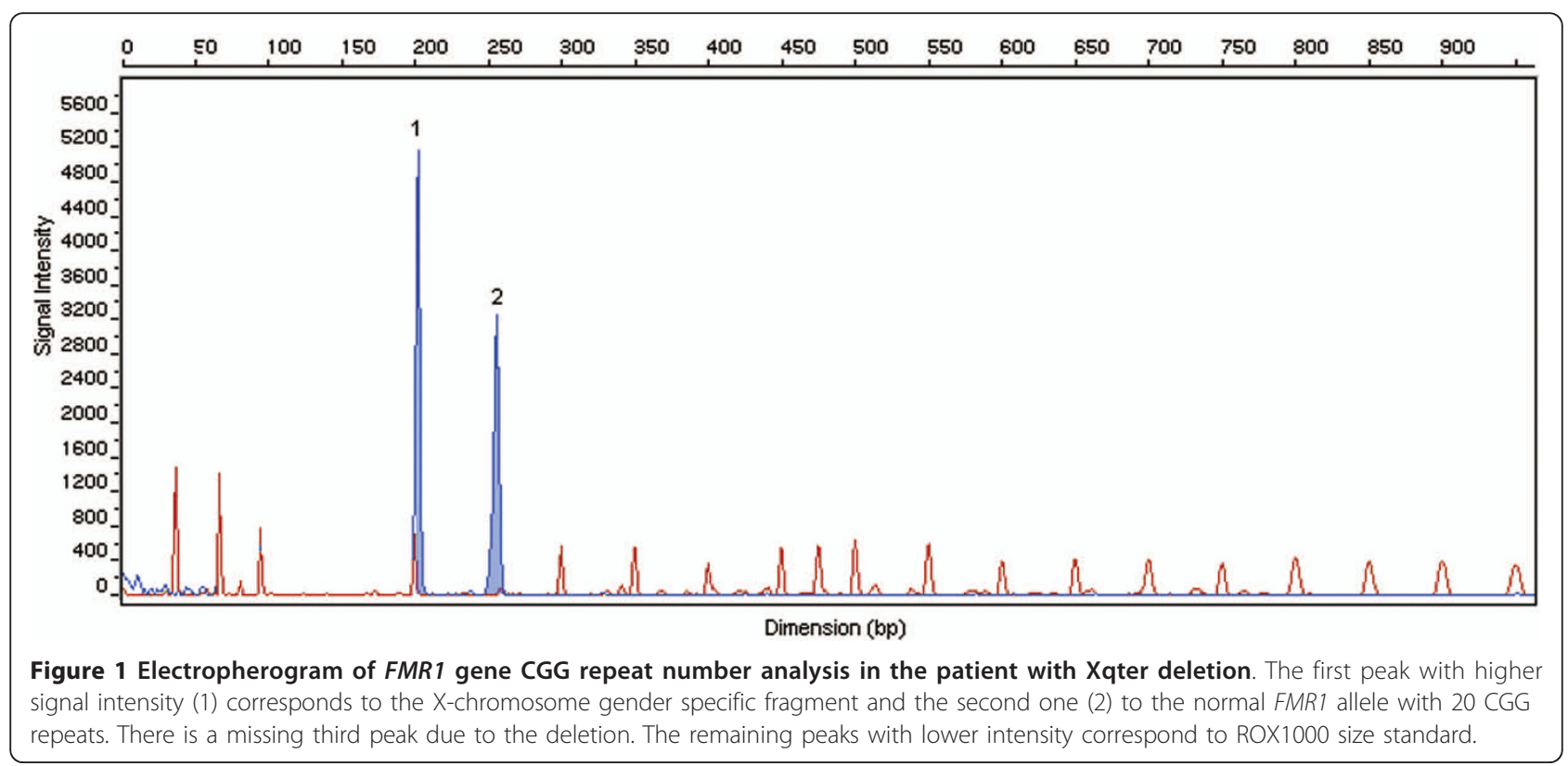



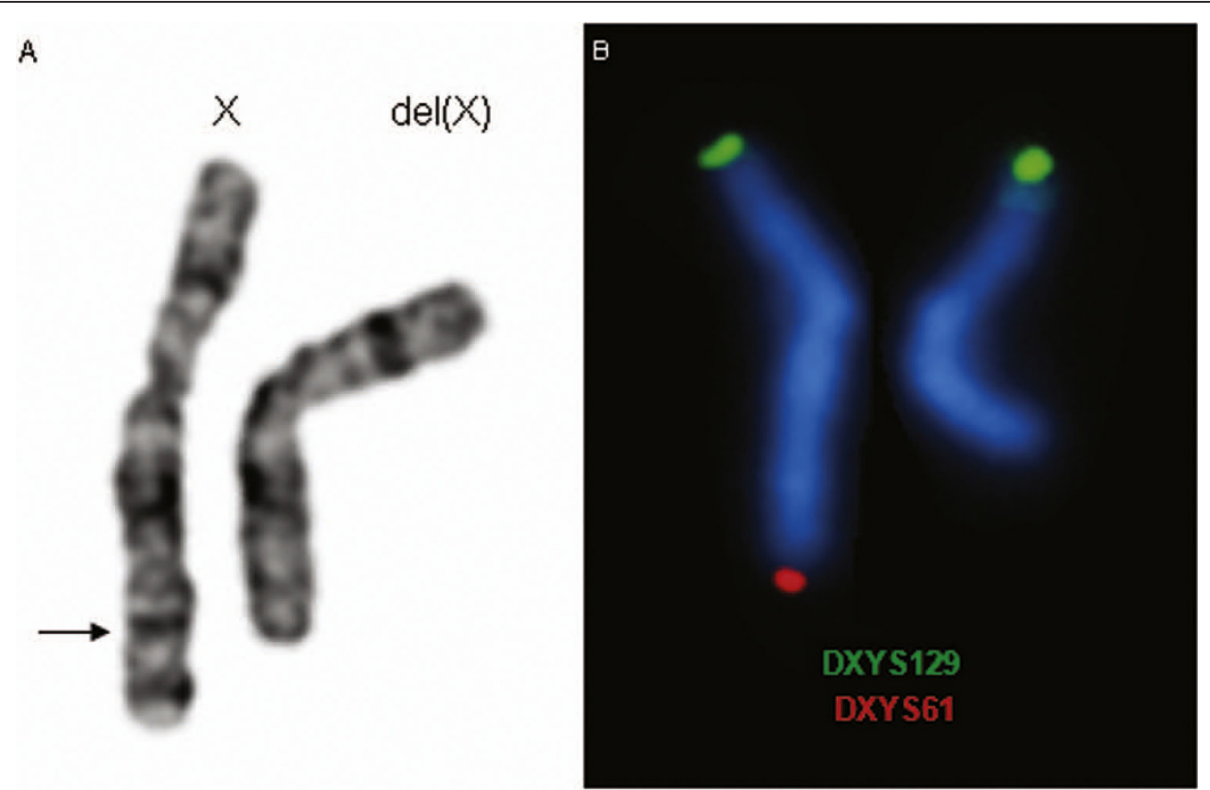

Figure 2 Conventional and molecular cytogenetics results. A - Partial karyogram of GTG banded X-chromosomes of the patient. The arrow indicates the region of the breakpoint in the X-chromosome. B - Dual colour FISH with the subtelomeric specific probes showing the normal Xchromosome and the deleted $\mathrm{X}$-chromosome (on the right).

methylation status of $0 \%$ (data not shown). FMR1 gene methylation analysis excluded allele drop out as a possible explanation for the presence of only one allele in the FMR1 CGG repeat number PCR analysis [13]. If two alleles were present, in a homozygous pattern (a) or a normal allele and a full mutation allele (b) the MSMLPA result would be clearly different. The existence of a second allele would always be detected by the presence of methylation, at a lower percentage due to normal X inactivation (a), or at a higher percentage in due to both $\mathrm{X}$ inactivation and full mutation allele methylation (b).

\section{Discussion}

$\mathrm{X}$-chromosome deletions have been associated with POF for more than a decade, with two X-chromosome regions, named POF1 and POF2, mainly associated with POF. POF1 region limits are not consensual among literature, as some authors define it as Xq23q27 [8], whereas others define it from Xq26 to Xq28 [14]. POF2 region is well established between Xq13.3q21 [7]. Most of X-chromosome abnormalities associated with POF described in this region are X;autosome balanced translocations, with $80 \%$ of the chromosome breakpoints disrupting Xq21 [15]. However, women with deletions involving this gene-poor region are not affected by POF, being the most plausible explanation a position effect on autosomal ovaryspecific genes translocated to the $\mathrm{X}$-chromosome, and not an involvement of X-linked genes [15].








POF1 region deletions are by far more common as being associated with POF, with several cases already described, and, in most of them, the same deletion is present in two or even three generations of the same family. As illustrated in Figure 5, Krauss et al. in 1987 reported an interstitial deletion 46,XX,del(X)(pter $\rightarrow$ q21.3::q27 $\rightarrow$ qter) in a three generation family affected by POF and in 1991 Veneman et al. reported a mother and her daughter, both with POF, and an Xq25 to Xqter deletion [16,17]. Davison et al. (1998) published a 46,X, $\operatorname{del}(\mathrm{X})$ (q26) karyotype in both mother and daughter with POF at 28 and 26 years old, respectively; Rosseti et al. (2004) reported an interstitial deletion 46,X,del(X)(q26 $\rightarrow$ q28) in two affected women, with secondary amenorrhea at 17 and 22 years old, and her mother, with POF at 43 years old $[18,19]$. Fimiani et al. (2006) also reported the case of both mother and daughter with POF at 43 and 26 years old, respectively, both with a 46 , $\mathrm{X}, \operatorname{del}(\mathrm{X})(\mathrm{q} 26.2 \mathrm{q} 28)$ karyotype, after the report by Eggerman et al. (2005) of a mother and daughter with a 46,X, $\operatorname{del}(\mathrm{X})(\mathrm{q} 27.2$ or q27.3) karyotype and POF at 36 and 28 years old, respectively $[20,21]$. The same figure illustrates four additional cases reported by Rizzolio [15]. These reports raise the question that factors other than the deletion might be involved in POF, since women with the same deletion manifest POF at a different

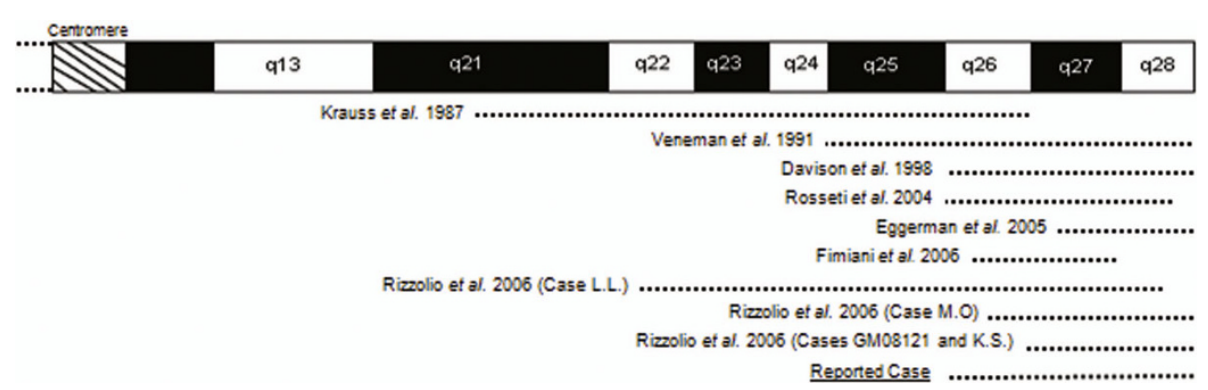

Figure $\mathbf{5}$ Schematic representation of $\mathbf{X q}$. The dotted lined represent the extension of the deletions described in the literature and of the reported case. 
age, and some are able to reproduce whereas others do not [19].

In the present case, the mother has a normal karyotype and as the father had already deceased, it was not possible to evaluate if the deletion was de novo or inherited from the father. However, this deletion in a male would be incompatible with life, and so, we can safely hypothesize that the deletion is de novo.

The absence of Fragile X syndrome features in this woman was quite intriguing to us since, with only one functional allele, which according to Lyon hypotheses should be inactivated in $50 \%$ of cells, there would be a reduction to half in FMRP levels [22]. A methylation assay performed to access the methylation status of the unique FMR1 allele present resulted in a negative methylation pattern. This allows us to conclude that the normal X-chromosome is active, whereas the deleted $\mathrm{X}$-chromosome was preferentially inactivated, explaining the absence of Fragile $\mathrm{X}$ symptoms, as there are normal levels of FMRP. Cells with the abnormal Xchromosome active would have a deficiency in gene products from the deleted region, explaining the negative selection against such cells, resulting in skewed Xchromosome inactivation (XCI) whenever there is a structural abnormality of one of the $\mathrm{X}$ homologous [22].

Carrel and Willard (2005) obtained, from fibroblast cells, an expression profile for the genes located in the inactive $\mathrm{X}$-chromosome $\left(\mathrm{X}_{\mathrm{i}}\right)$ revealing that about $25 \%$ of genes escape inactivation being expressed at different levels and from different regions of the chromosome [23]. One of such clusters of genes expressed from $X_{i}$ maps to the gene-rich region $\mathrm{Xq} 28$, where the expression level may reach 50\% [23].

Altogether, these results suggest that haploinsuffiency of the genes located in the deleted region is a promising explanation for the POF scenario, especially when it involves Xq28. The lack of expression of those deleted genes that normally escape $\mathrm{X}$ inactivation may compromise ovarian function. To further evaluate this situation it would be important to perform $\mathrm{X}$ inactivation status assays in every women with $\mathrm{X}$-chromosome deletion and POF, and, as if expected, a skewed XCI pattern is observed, this would further support the hypothesis of haploinsufficiency of the deleted genes. MS-MLPA for FMR1 gene can be a valuable tool for this assessment, whenever deletion involves Xq27 region, as it is a fast and easy to perform technique, allowing the achievement of precise results. Oral contraceptives prescribed to our patient might have delayed the diagnosis of the POF condition that could have manifested earlier taking into account her menstrual patterns. This suggests that contraceptive therapy provided her the adequate hormonal levels and mitigate the menopausal symptoms due to an eventual ovarian insufficiency, what may imply that genes involved in the deletion can have a function at this level. One of the patients reported by Rosseti et al. (2004) has a similar clinical history, as she had irregular menses, started to take pill at 19, and when she stopped, at 22 years old, she had amenorrhea [19]. Yeshaya and colleagues interestingly reported that microdeletion syndromes could be associated with altered replication patterns of genes not associated with the aberrant chromosome [12]. We can not discard that the $\mathrm{Xq}$ terminal deletion observed in our patient causes altered replication timing of genes associated with POF. However, if this would be the case, other X-chromosome deletions would be associated with POF. It would be interesting to study the replication time of other patients with POF due to X deletions [24].

The time during development when skewed X-chromosome inactivation takes place can also influence the onset of POF, since woman with the same deletion manifest POF at different ages and sometimes with different severities. Understanding how this happens and which gene(s) are necessary in a double dosage expression can lead to an improvement in reproductive knowledge and to the implementation of strategies to delay or prevent premature ovarian failure, allowing women to preserve her reproductive life.

Nevertheless, it is thought that $5-10 \%$ of these women will be able to conceive and will need appropriate advice due to high risk of fragile $\mathrm{X}$ syndrome or POF in their descendents [25]. Preconceptual counseling should be offered to those women giving them full disclosure about the risks of transmitting the disease and possible preventive measures [25]. In addition, prenatal testing through amniocentesis or chorionic villus sampling should be recommended for pregnant women carriers of the fragile $\mathrm{X}$ mutation or premutation.

Recently new assisted reproduction techniques associated with preimplantation genetic diagnosis (PGD) performed after an in-vitro fertilization cycle (IVF), gave the opportunity for a selection of embryos free of the premutation or full mutation [25].

In our case, at the present time, the only reproductive alternatives that could be undertaken include IVF with oocyte donation or allotransplantation of ovarian tissue.

To summarize, these data reflect how important it is to report all cases with POF and X-chromosome deletions and their complete clinical history, in order to highlight a pattern and try to understand which regions are in fact crucial for normal ovarian development. Special attention should be paid to Xq28 region due to the knowledge that genes on this region escape from methylation in the $X_{i}$ and also due to the increased number of POF patients with deletions involving this region. 


\section{Materials and methods Subject}

A 29 year old woman was referred from the gynecology department of our local maternity due to premature ovarian failure. She had menarche at 11 years, experienced oligomenorrhea and at 14 years old she fulfilled the diagnosis criteria for polycystic ovarian syndrome and received a prescription of oral contraceptives. Trying to get pregnant, she suspended medication 15 years later, but she neither got pregnant or menstruated again. Hormonal analysis revealed an FSH level of 155.5 $\mathrm{mIU} / \mathrm{ml}, \mathrm{LH}$ of $62.7 \mathrm{mIU} / \mathrm{ml}$ and $16 \mathrm{pg} / \mathrm{ml}$ for $\mathrm{E}_{2}$. The patient had no history of autoimmune diseases or surgeries. Her mother did not report a past history of subfertility and experienced menopause at 50 years. This woman is part of a group of patients with premature ovarian failure recruited for a study to access the association between this condition and FMR1 gene CGG repeat number. The study was approved by the medical board of the hospital and all participants gave their written informed consent.

\section{FMR1 gene CGG repeats determination}

Genomic DNA was extracted from peripheral blood lymphocytes using Jetquick blood and cell culture DNA Midi Spin kit (Genomed, Löhne, Germany). DNA concentration and purity were measured using a NanoDrop1000 Spectrophotometer (Thermo Scientific, Waltham, USA). The sample was analysed with Abbot Fragile X kit (Abbot, Illinois, USA), which consists of a PCR reaction specific to determine the number of CGG repeats present at FMR1 gene. A PCR reaction of $20 \mu \mathrm{l}$ of final volume containing $13 \mu \mathrm{l}$ of High GC PCR Buffer, $0.8 \mu \mathrm{l}$ of FMR1 primers, $0.6 \mu \mathrm{l}$ of gender primers, $1.2 \mu \mathrm{l}$ of TR PCR enzyme mix and $3 \mu \mathrm{l}$ of genomic DNA (67 ng/ul) was performed in an Applied Biosystems ABI 2720 Thermal Cycler (Applied Biosystems, Foster City CA, USA). The PCR conditions used were 15 cycles of $98.5^{\circ} \mathrm{C}$ for $10 \mathrm{~s}, 58^{\circ} \mathrm{C}$ for $1 \mathrm{~min}$ and $75^{\circ} \mathrm{C}$ for $6 \mathrm{~min}$, followed by 15 cycles starting at $98.5^{\circ} \mathrm{C}$ for 10 s, $56^{\circ} \mathrm{C}$ for $1 \mathrm{~min}$ and $75^{\circ} \mathrm{C}$ for $6 \mathrm{~min}$. PCR products were purified with CleanUp Enzyme mix and the alleles were sized using an automated sequencer ABI Prism 310Genetic Analyser (Applied Biosystems) by comparison with the size standard Rox1000, both products from Abbott (Abbott).

\section{Cytogenetic analysis}

Peripheral blood samples were collected and metaphase chromosomes were prepared according to standard cytogenetic procedures [26]. GTG high resolution banded chromosomes were analyzed using a Nikon Eclipse microscope (Nikon Instruments, Badhoevedorp,
Netherlands) coupled with the Cytovision system (Applied Imaging International Lda, Newcastle upon Tyne, UK).

\section{Fluorescence in situ hybridization}

Fluorescence in situ hybridization (FISH) was performed according to standard procedures, using specific probes for subtelomeric Xq (DXYS61) and Xp (DXYS129) (Cytocell, Cambridge, UK) chromosomal regions. A total of 10 metaphases were analyzed with a Nikon Eclipse fluorescence microscope (Nikon) coupled with the Cytovision system (Applied Imaging International Lda).

To further characterize the breakpoint, multicolour banding (MCB) was performed using seven partial chromosome painting (pcp) probes described in Weise et al. 2008 [27]. The 10 metaphases scored were analysed using a Zeiss Axioplan fluorescence microscope (Zeiss, Jena, Germany) with MetaSystems (Isis) software (Altlussheim, German). Six BAC (bacterial artificial chromosomes) clones were also used in order to clarify the breakpoint. The analysis software was the same used for MCB. Table 1 summarizes the BAC clones used and their location on the $\mathrm{X}$-chromosome.

\section{FMR1 methylation analysis}

Methylation-Specific Multiplex Ligation-Dependent Probe Amplification (MS-MLPA) was performed using the SALSA MS-MLPA MEO29-B1 kit (MRC-Holland, Amsterdam, Netherlands). Genomic DNA, 300 ng, was mixed with $1 \mu \mathrm{l}$ of denaturation buffer and MLPA protocol was performed according to the manufacturers' instructions. PCR reactions were carried out on an Applied Biosystems ABI 2720 Thermal Cycler (Applied Biosystems). Samples were analysed by capillary electrophoresis on an ABI Prism 310 Genetic Analyser (Applied Biosystems) and Genescan software (Applied Biosystems) was used to extract the quantitative data. These were analyzed with Coffalyser analysis software (MRC-Holland, Amsterdam, Netherlands) to determine methylation status.

The aim of this analysis was to determine the degree of methylation of the only FMR1 allele present, localized

Table 1 Characteristics of the BAC clones used for FISH analysis

\begin{tabular}{ccccc}
\hline Clone & Start (Mb) & End (Mb) & Location & Insert Size (bp) \\
\hline RP4-753P9 & 128,544 & 128,660 & Xq25 & 116560 \\
\hline RP11-1118 & 133,964 & 134,153 & Xq26.3 & 188357 \\
\hline RP1-48G12 & 141,595 & 141,794 & Xq27.3 & 199015 \\
\hline RP11-103M23 & 153,345 & 153,519 & Xq28 & 174233 \\
\hline
\end{tabular}

Built at the UCSC Genome Browser, version NCBI3537/hg17 and accessed at June $26^{\text {th }} 2010$. 
on the normal X-chromosome. MS-MLPA uses the methylation-sensitive restriction enzyme HhaI to determine the degree of methylation, by comparing digested and undigested samples of the same patient. Unmethylated probes with HhaI recognition site will be digested, and hence will disappear in the sample subject to digestion, whereas methylated probes won't be digested and, thus, will be present after PCR amplification. As the subject has only one allele, the degree of methylation of FMR1 gene is indicative of the degree of methylation of the normal X-chromosome.

\section{Acknowledgements}

We thank the patient for her collaboration.

\section{Author details}

'Laboratório de Citogenética, Instituto de Biologia Médica, Faculdade de Medicina, Universidade de Coimbra, 3000-354 Coimbra, Portugal. ${ }^{2}$ Serviço de Ginecologia, Maternidade Bissaya Barreto, 3000-061 Coimbra, Portugal. ${ }^{3}$ Jena University Hospital, Institute of Human Genetics and Anthropology, D007740 Jena, Germany. ${ }^{4} \mathrm{CIMAGO}$, Universidade de Coimbra, 3001-301 Coimbra, Portugal. ${ }^{5}$ Centro de Neurociências e Biologia Celular, Universidade de Coimbra, 3000-354 Coimbra, Portugal.

\section{Authors' contributions}

SIF- Participated in the design of the study, carried out the molecular biology work and drafted the manuscript.

EM- Participated in the design of the study and carried out the subtelomeric FISH experiments.

MP - Carried out the cytogenetic work

JA - Contributed with clinical information.

TL - Carried out MCB and BAC-FISH experiments and revised critically the manuscript.

JBM- Has been involved in the design of the study and drafting of the manuscript, revising it critically for important intellectual content.

IMC - Coordinated and conceived the study, being involved in the critical revision of the manuscript for important intellectual content.

All authors have read and approved the final manuscript.

\section{Competing interests}

The authors declare that they have no competing interests.

Received: 26 May 2010 Accepted: 20 July 2010 Published: 20 July 2010

\section{References}

1. Miano MG, Laperuta C, Chiurazzi P. D'Urso M, Ursini MV: Ovarian dysfunction and FMR1 alleles in a large Italian family with POF and FRAXA disorders: case report. BMC Med Genet 2007, 8:18.

2. Simpson $J \mathrm{~L}$, Rajkovic A: Ovarian differentiation and gonadal failure. Am Med Genet 1999, 89:186-200.

3. Welt CK, Smith PC, Taylor AE: Evidence of Early Ovarian Aging in Fragile $X$ Premutation Carriers. J Clin Endocrinol Metab 2004, 89:4569-4574.

4. Portnoi MF, Aboura A, Tachdjian G, Bouchard P, Dewailly D, Bourcigaux N, Frydman R, Reyss A, Brisset S, Christin-Maitre S: Molecular cytogenetic studies of Xq critical regions in premature ovarian failure patients. Hum Reprod 2006, 21:2329-2334

5. Goswami D, Conway GS: Premature ovarian failure. Hum Reprod Update 2005, 11:391-410.

6. Beck-Peccoz P, Persani L: Premature ovarian failure. Orph J Rare Dis 2006, 1:9.

7. Powell $C M$, Taggart RT, Drumheller TC, Wangsa D, Qian C, Nelson LM, White BJ: Molecular and cytogenetic studies of an $\mathrm{X}_{\text {; }}$ autosome translocation in a patient with premature ovarian failure and review of the literature. Am J Med Genet 2004, 52:19-26.

8. Therman E, Laxova R, Susman B: The critical region on the human Xq Hum Genet 1990, 85:455-461.
9. Toniolo D: X-linked premature ovarian failure: a complex disease. Curr Opin Genet Dev 2006, 16:293-300.

10. Pandey UB, Phadke SR, Mittal B: Molecular diagnosis and genetic counseling for fragile $X$ mental retardation. Neurol India 2004, 52:36-42.

11. Sullivan AK, Marcus M, Epstein MP, Allen EG, Anido AE, Paquin JJ, YadavShah M, Sherman SL: Association of FMR1 repeat size with ovarian dysfunction. Hum Reprod 2005, 20:402-412.

12. Allen EG, Sullivan AK, Marcus M, Small C, Dominguez C, Epstein MP, Charen K, He W, Taylor KC, Sherman SL: Examination of reproductive aging milestones among women who carry the FMR1 premutation. Hum Reprod 2007, 22:2142-2152.

13. Khaniani MS, Kalitsis P, Burgess T, Slater HR: An improved Diagnostic PCR Assay for identification of Cryptic Heterozygosity for CGG Triplet Repeat Alleles in the Fragile X Gene (FMR1). Mol Cytogenet 2008, 1:5.

14. Tharapel AT, Anderson KP, Simpson JL, Martens PR, Wilroy RS Jr, Llerena JC $\mathrm{Jr}$, Schwartz CE: Deletion (X)(q26.1>q28) in a proband and her mother: molecular characterization and phenotypic-karyotypic deductions. Am J Hum Genet 1993, 52:463-471.

15. Rizzolio F, Bione S, Sala C, Goegan M, Gentile M, Gregato G, Rossi E, Pramparo T, Zuffardi O, Toniolo D: Chromosomal rearrangements in Xq and premature ovarian failure: mapping of 25 new cases and review of the literature. Hum Reprod 2006, 21:1477-1483.

16. Krauss CM, Turksoy RN, Atkins L, McLaughlin C, Brown LG, Page DC: Familial premature ovarian failure due to an interstitial deletion of the long arm of the X chromosome. N Engl J Med 1987, 317:125-131.

17. Veneman F, Beverstock GC, Exalto N, Mollevanger P: Premature menopause because of an inherited deletion in the long arm of the $\mathrm{X}$ chromosome. Fertil Steril 1991, 55:631-633.

18. Davison RM, Quilter CR, Webb J, Murray A, Fisher AM, Valentine A, Serhal P, Conway GS: A familial case of $X$ chromosome deletion ascertained by cytogenetic screening of women with premature ovarian failure. Hum Reprod 1998, 13:3039-3041.

19. Rossetti F, Rizzolio F, Pramparo T, Sala C, Bione S, Bernardi F, Goegan M, Zuffardi O, Toniolo D: A susceptibility gene for premature ovarian failure (POF) maps to proximal Xq28. Eur J Hum Genet 2004, 12:829-834.

20. Fimiani G, Laperuta C, Falco G, Ventruto V, D'Urso M, Ursini MV, Miano MG: Heterozygosity mapping by quantitative fluorescent PCR reveals an interstitial deletion in Xq26.2-q28 associated with ovarian dysfunction. Hum Reprod 2006, 21:529-535.

21. Eggermann T, Meschede D, Schuler H, Palm S, Glaser D, Horsthemke B, Eggermann K, Haverkamp F, Zerres K: Premature ovarian failure associated with a small terminal $X q$ deletion: narrowing the POF1 region down to Xq27.2/Xq27.3-qter. Clin Genet 2005, 67:434-437.

22. Lyon MF: X-chromosome inactivation and human genetic disease. Acta Paediatr Suppl 2002, 439:107-112.

23. Carrel L, Willard HF: $X$-inactivation profile reveals extensive variability in X-linked gene expression in females. Nature 2005, 434:400-404.

24. Yeshaya J, Amir I, Rimon A, Freedman J, Shohat M, Avivi L: Microdeletion syndromes disclose replication timing alterations of genes unrelated to the missing DNA. Mol Cytogenet 2009, 2:11.

25. Martin JR, Arici A: Fragile $X$ and reproduction. Curr Opin Obstet Gynecol 2008, 20:216-220

26. Rooney DE, Czepulkowski BH: Human Cytogenetics: A Practical Approach. New York, Oxford University Press, Second 1992

27. Weise A, Mrasek K, Fickelscher I, Claussen U, Cheung SW, Cai WW, Liehr T, Kosyakova N: Molecular Definition of High-resolution Multicolor Banding Probes: First Within the Human DNA Sequence Anchored FISH Banding Probe Set. J Histochem Cytochem 2008, 56:487-493.

doi:10.1186/1755-8166-3-14

Cite this article as: Ferreira et al: X-chromosome terminal deletion in a female with premature ovarian failure: Haploinsufficiency of $X$-linked genes as a possible explanation. Molecular Cytogenetics 2010 3:14. 